\title{
The efficacy and safety of lodine-131- metaiodobenzylguanidine therapy in patients with neuroblastoma: a meta-analysis
}

\author{
Huihui He, Qiaoling Xu and Chunjing Yu*
}

\begin{abstract}
Objective: Neuroblastoma is a common extracranial solid tumor of childhood. Recently, multiple treatments have been practiced including lodine-131-metaiodobenzylguanidine radiation $\left({ }^{131} \mathrm{I}-\mathrm{MIBG}\right)$ therapy. However, the outcomes of efficacy and safety vary greatly among different studies. The aim of this meta-analysis is to evaluate the efficacy and safety of ${ }^{131}$ I-MIBG in the treatment of neuroblastoma and to provide evidence and hints for clinical decision-making.

Methods: Medline, EMBASE database and the Cochrane Library were searched for relevant studies. Eligible studies utilizing ${ }^{131}$ I-MIBG in the treatment of neuroblastoma were included. The pooled outcomes (response rates, adverse events rates, survival rates) were calculated using either a random-effects model or a fixed-effects model considering of the heterogeneity.
\end{abstract}

Results: A total of 26 clinical trials including 883 patients were analyzed. The pooled rates of objective response, stable disease, progressive disease, and minor response of ${ }^{131}$ I-MIBG monotherapy were 39\%, 31\%, 22\% and 15\%, respectively. The pooled objective response rate of ${ }^{131} \mathrm{I}-\mathrm{MIBG}$ in combination with other therapies was $28 \%$. The pooled 1 -year survival and 5 -year survival rates were $64 \%$ and $32 \%$. The pooled occurrence rates of thrombocytopenia and neutropenia in MIBG monotherapy studies were $53 \%$ and $58 \%$. In the studies of ${ }^{131}$ I-MIBG combined with other therapies, the pooled occurrence rates of thrombocytopenia and neutropenia were $79 \%$ and $78 \%$.

Conclusion: ${ }^{131} \mathrm{I}-\mathrm{MIBG}$ treatment alone or in combination of other therapies is effective on clinical outcomes in the treatment of neuroblastoma, individualized ${ }^{131}$ I-MIBG is recommended on a clinical basis.

Keywords: ${ }^{131} \mathrm{I}-\mathrm{MIBG}$, Neuroblastoma, Neuroendocrine tumor, Clinical trials, Meta-analysis

\section{Introduction}

Neuroblastoma is a common extracranial solid tumor of childhood, accounting for approximately $8 \%$ of total pediatric malignant tumors $[1,2]$. It derives from primitive sympathetic nervous system tissue and arises mostly from adrenal medulla or paraspinal ganglia of the neck, chest, abdomen, or pelvis [3]. Statistically, neuroblastoma occurs more common in boys than in girls, however, the

*Correspondence: ycjwxd1978@jiangnan.edu.cn

Department of Nuclear Medicine, Affiliated Hospital of Jiangnan University, Wuxi, China potential causes remain long-standing mysteries [4]. Furthermore, over one-third of the patients are diagnosed at the age of $<12$ months and the median age at diagnosis is 17 months More than $50 \%$ of children present with widely metastatic disease [5].

The type of therapy for neuroblastoma depends on risk group in which a patient identifies [5, 6]. Risk stratification is determined according to a patient's International Neuroblastoma Risk Group (INRG) stage, age, histological condition of tumor, degree of tumor differentiation, and et al [6]. Typically, in low-risk patients may be monitored for spontaneous differentiation or regression 
of tumor and either chemotherapy or radiation may not be necessary in these patients. Conversely, chemotherapy may be used in patients with intermediate or high risk. Moreover, patients with high risk may receive stem cell transplant, immunotherapy and surgery.

Despite multiple choices of treatment mentioned above, patients with neuroblastoma continue to be at high risk of treatment failure [7-10]. Unfortunately, patients with refractory or relapsed neuroblastoma suffer from poor prognosis, while novel therapy is in need [11]. Currently, there is no consensus on the optimal treatment for neuroblastoma.

Meta-iodobenzylguanidine (MIBG) is an analogue of adrenergic neuron blockers, it shows high affinity to cells of the sympathetic nervous system and by neoplasms arised from them, such as neuroblastoma [9]. Interestingly, Iodine-131 labeled MIBG ( $\left.{ }^{131} \mathrm{I}-\mathrm{MIBG}\right)$ was used to treat neuroendocrine tumors including neuroblastoma after the development of MIBG $[12,13]$. Since then, findings on the treatment role of ${ }^{131}$ I-MIBG have occurred $[14,15]$. The first I-131 MIBG therapy for neuroblastoma were reported in 1986 [16]. In the following years, several other groups also conducted phase I or phase II clinical trials on the efficacy and safety of ${ }^{131}$ I-MIBG on the treatment of neuroblastoma. However, the objective response (partial or complete response) rate varied widely, from $30 \%$ to $71 \%[14,15,17-24]$.

As far as we are concerned, a few studies limited to small sample sizes and heterogeneity of treatment outcomes have investigated the efficacy of ${ }^{131}$ I-MIBG for the treatment of neuroblastoma. The aim of this study was to conduct a meta-analysis by collating the available evidence to generate an accurate and sounding assessment of the efficacy and safety of ${ }^{131}$ I-MIBG monotherapy and ${ }^{131}$ I-MIBG in combination with other agents, and subsequently to provide evidence and hints for clinical implement and decision-making.

\section{Materials and Methods Statement}

This meta-analysis was entirely based on previous published studies which had declared ethical approvals, and no original clinical raw data of the published results were collected or utilized, thereby ethical approval was not conducted for this study. This review was conducted on the basis of the Preferred Reporting Items for Systematic Reviews and Meta-analysis (PRISMA) [25].

\section{Literature search and selection criteria}

We conducted a comprehensive literature search of online databases of the Medline (via PubMed), Embase database and the Cochrane Library from inception to May 31, 2021. Our search strategy was (("Iodine
Radioisotopes"[Mesh] OR ("iodine radioisotopes"[MeSH Terms] OR ("iodine"[All Fields] AND "radioisotopes"[All Fields]) OR "iodine radioisotopes"[All Fields] OR "therapy"[All Fields]) AND " neuroblastoma "[All Fields]. Additionally, we manually searched the reference lists of all accepted papers to ensure that no studies were missed. All articles were published in English. Studies that met the following criteria were enrolled for this meta-analysis: (1) clinical trials designed to evaluate the efficacy of ${ }^{131}$ I-MIBG or ${ }^{131}$ I-MIBG in combination with other therapies (radiation sensitizer, myeloablative chemotherapy, etc.) in untreated, relapsed or refractory neuroblastoma; (2) data available for the extraction or calculation tumor treatment response rates, survival and adverse events. Once studies recruited participants over the same period or from the same study centers, only the study with the largest sample size or yielding the most pertinent outcomes was included to avoid duplications. All the potentially relevant papers were reviewed independently by two investigators ( $\mathrm{HH}$ and $\mathrm{QX})$ and disagreement were resolved by discussion and a third reviewer (CY) was involved in case that no consensus was achieved.

\section{Data extraction and quality assessments}

Two independent reviewers screened the titles and abstracts of articles to judge whether they meet the inclusion criteria. Thereafter a full-text reading of the literature was performed for the final inclusion. Details on patients' characteristics, ${ }^{131}$ I-MIBG dose and schedule, tumor response rates were also extracted independently by two investigators. The main clinical endpoints were tumor response rate, including complete response (CR), partial response (PR), progressive disease (PD), stable disease $(\mathrm{SD})$, minor response (MR), survival rates, and adverse events (AEs) rates. Objective response was defined as patients either undergo a partial or complete response. Event-free survival (EFS) rates and overall survival (OS) rates in each study was also extracted. We used the Newcastle-Ottawa Quality Assessment Scale to assess the methodological quality of enrolled studies [26]. The Newcastle-Ottawa Quality Assessment Scale contains 3 categories (quality selection, comparability and outcome) across which cohort studies are assessed for quality.

\section{Statistical analysis}

All statistical analyses were conducted using R 4.1.2 software package. The efficacy and safety of ${ }^{131}$ I-MIBG treatment in neuroblastoma was assessed depending on the indicators aforementioned. A Cochran Q test was used to assess heterogeneity between studies and $\mathrm{I}^{2}$ statistic was used to investigate the magnitude of the heterogeneity. Pooled rates of objective response, SD, PD, MR, 
1-year survival, 5-year survival, AEs and their respective 95\% confidence intervals (CIs) were calculated with a random-effects model or a fixed-effects model. If $\mathrm{I}^{2}$ value was $>50 \%$, a random-effects model was used, otherwise we used a fixed-effects model [27]. A sensitivity analysis was conducted in order to check the stability of pooled outcomes. Furthermore, an Egger's test was performed to assess the potential publication bias. A two-tailed P value $<0.05$ was regarded as statistically significant.

\section{Results}

\section{Identification of relevant studies}

A total of 1102 articles were identified from the process of database search. A total of 26 articles were identified for analysis. Figure 1 shows the details of the literature search and study selection process. The enrolled 26 studies containing a total of 883 patients with diagnosed neuroblastoma, provided relevant outcomes that met the inclusion criteria in this meta-analysis. The majority of these studies did not have a control group. These clinical trials were conducted in UK, USA, Italy, Thailand, Japan and Netherlands. All studies included demonstrated low risk of bias. More details of the studies included was shown in Table 1.

\section{Efficacy of ${ }^{131}$ I-MIBG monotherapy}

The numbers of articles included in the evaluation of rates of objective response, SD, PD and MR were $17,14,13$ and 8 , respectively. The objective response rates ranged from $30 \%$ to $71 \%$. The pooled objective response rate was 39\% (95\% CI: 32\%-47\%) as calculated utilizing the random-effects model. The pooled

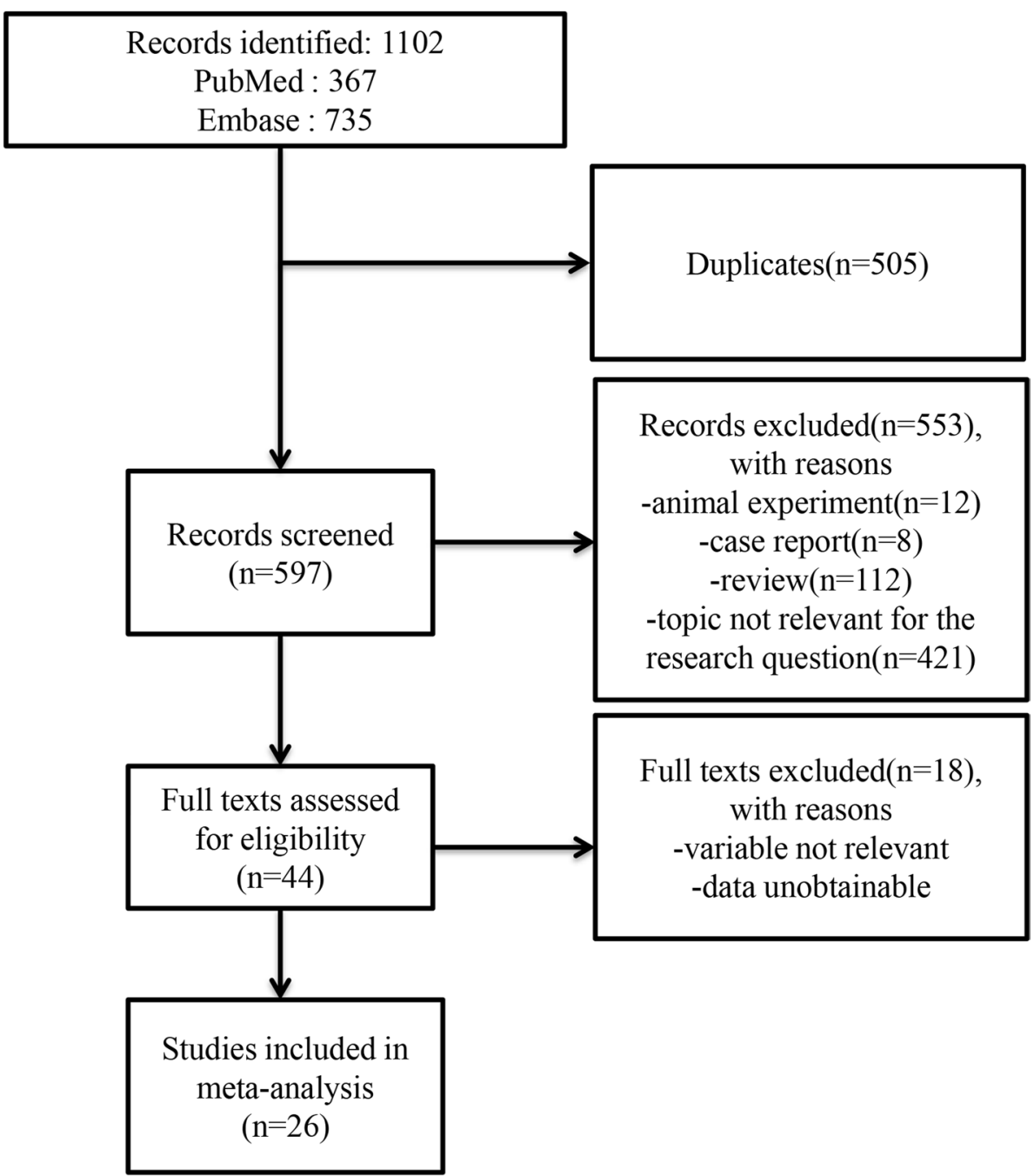

Fig. 1 Flow diagram of study selection process 


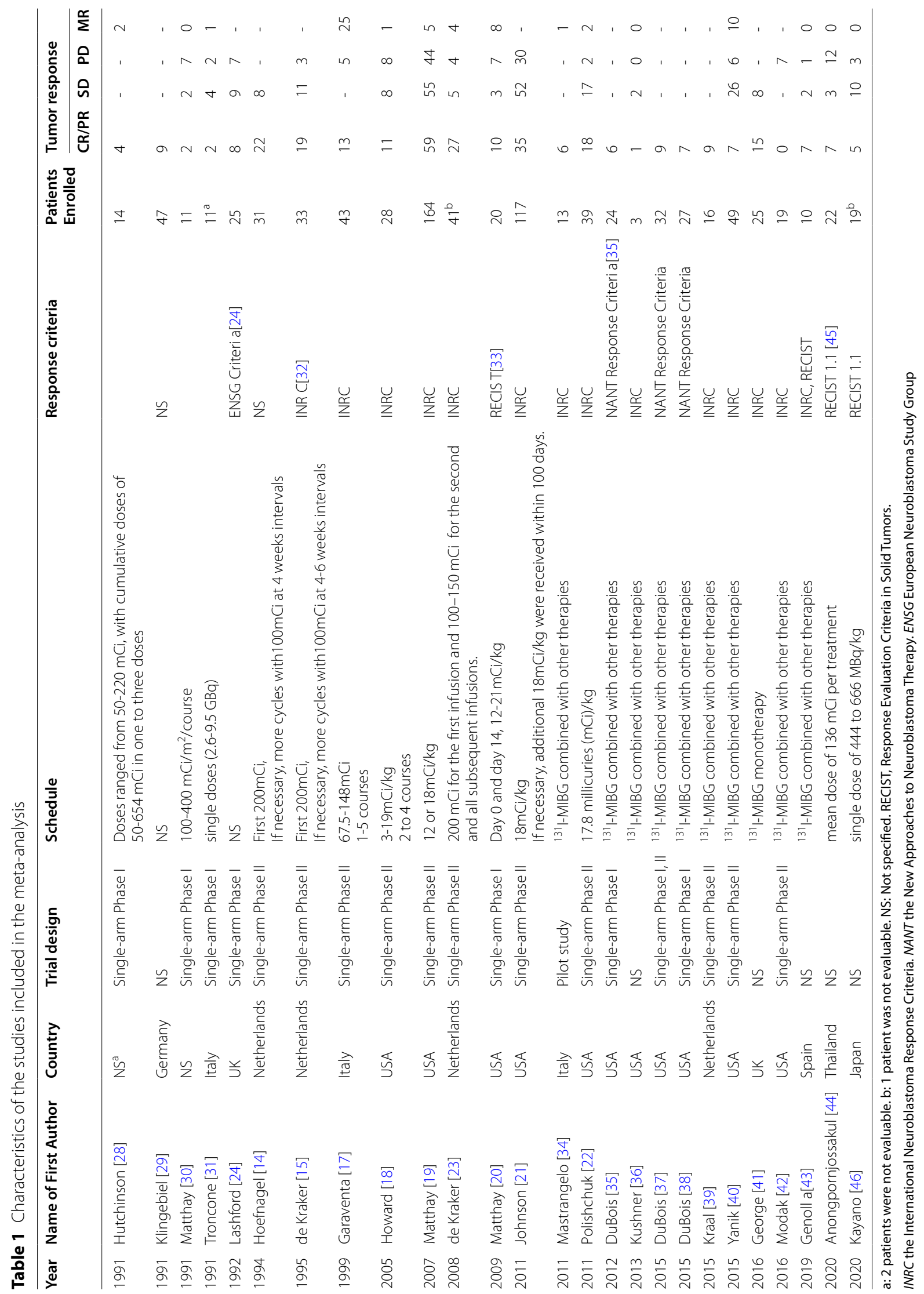


rates of SD, PD and MR were $31 \%$ (95\% CI: $24 \%, 37 \%$ ), $22 \%$ (95\% CI: $15 \%, 30 \%)$ and 15\% (95\% CI: 3\%, 31\%), respectively (Fig. 2).

\section{Efficacy of ${ }^{131}$ I-MIBG combined with other therapies}

Nine studies investigating the efficacy and safety of ${ }^{131}$ I-MIBG in combination with other therapies were included. Two studies reported the combination of ${ }^{131}$ I-MIBG and radiation sensitizer, 7 studies reported the combined employment of ${ }^{131}$ I-MIBG with chemotherapeutic agents namely cisplatin, cyclophosphamide, etoposide, vincristine, doxorubicin, irinotecan, and topotecan. The pooled objective response rate of ${ }^{131}$ I-MIBG in combination with other therapies was $28 \%$ (95\% CI: $14 \%, 44 \%)$. The pooled rates of SD, PD and MR were 48\% (95\% CI: 34\%, 62\%), 14\% (95\% CI: $6 \%, 24 \%)$ and $11 \%(95 \%$ CI: $3 \%, 20 \%)$, respectively (Fig. 3). The pooled objective response rate of ${ }^{131}$ I-MIBG in combination with chemotherapy was $35 \%$ (95\% CI: $20 \%, 52 \%$ ).

\section{Survival}

The pooled 1-year survival and 5-year survival rates were 64\% (95\% CI: 51\%, 75\%) and 32\% (95\% CI: 20\%, 46\%) (Fig. 4). Three studies reported median event-free survival which ranged from 10 to 16 months.

\section{Toxicity}

With regard to AEs rates, the major toxicity reported by studies included was hematologic, thrombocytopenia and neutropenia were the most frequently reported. The pooled occurrence rates of thrombocytopenia and neutropenia in MIBG monotherapy studies were 53\% (95\% CI: $35 \%, 71 \%)$ and $58 \%$ (95\% CI: 30\%, 84\%), respectively. As in the studies of ${ }^{131}$ I-MIBG combined with other therapies, the pooled occurrence rates of thrombocytopenia and neutropenia were $79 \%$ (95\% CI: 55\%, 95\%) and 78\% (95\% CI: 67\%, 88\%), respectively (Fig. 5).

\section{Heterogeneity and publication bias}

The results of the heterogeneity tests in rates of objective response, $\mathrm{SD}, \mathrm{PD}, \mathrm{MR}$, and occurrence rates of

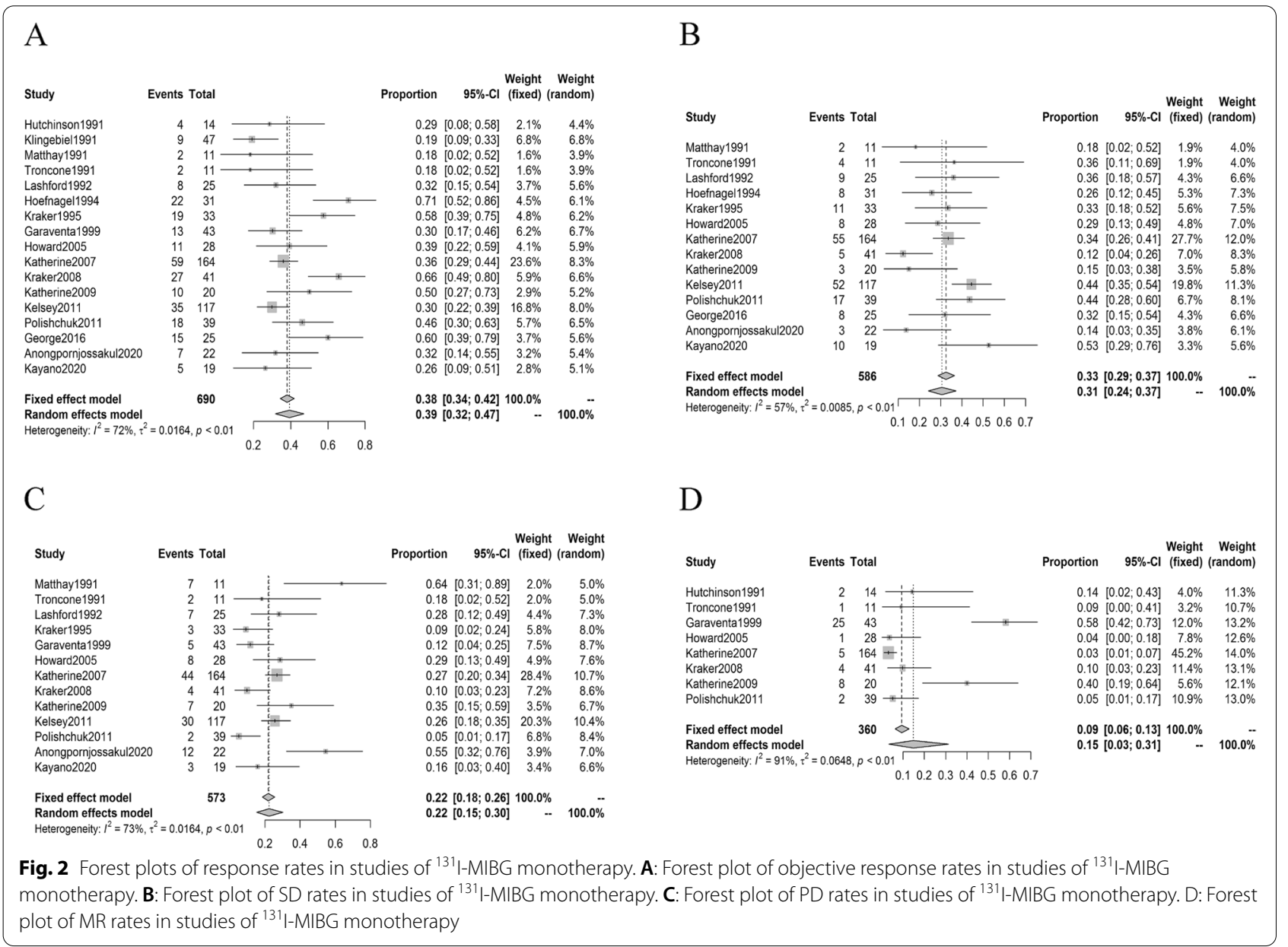




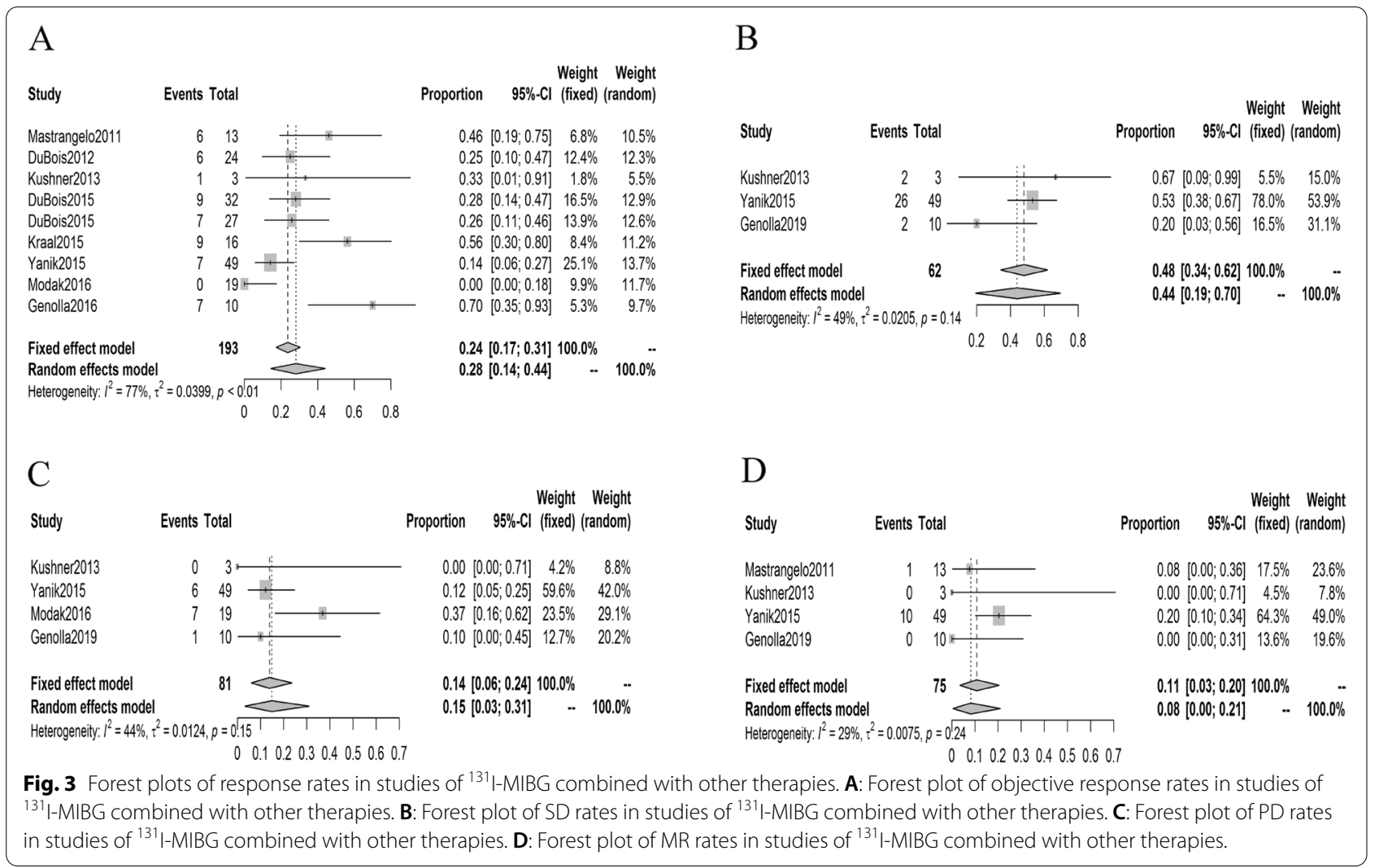

thrombocytopenia and neutropenia in studies of ${ }^{131}$ I-MIBG monotherapy were as follows: $\mathrm{I}^{2}=72 \%(p<$ $0.01), \mathrm{I}^{2}=57 \%(p<0.01), \mathrm{I}^{2}=73 \%(p<0.01) \mathrm{I}^{2}=91 \%$ $(p<0.01), \mathrm{I}^{2}=92 \%(p<0.01)$ and $\mathrm{I}^{2}=92 \%(p<0.01)$ (see Figs. 2 and 5). In the pooled analysis of studies of ${ }^{131}$ I-MIBG combined with other therapies, the $\mathrm{I}^{2}$ values of objective response, $\mathrm{SD}, \mathrm{PD}, \mathrm{MR}$, and occurrence rates of thrombocytopenia and neutropenia were $77 \%$ ( $\mathrm{p}<$ $0.01), 49 \%$ ( $p=0.14), 44 \%$ ( $p=0.15), 29 \%$ ( $p=0.24), 73 \%$ $(p=0.03)$ and $57 \%(p=0.10)$ (see Figs. 3,5$)$. Egger's tests for publication bias yielded $p$ values of $0.614,0.240,0.834$, $0.243,0.1761$ and 0.5356 for rates of objective response, $\mathrm{SD}, \mathrm{PD}, \mathrm{MR}$ and occurrence rates of thrombocytopenia and neutropenia in studies of ${ }^{131}$ I-MIBG monotherapy. In the pooled analysis of studies of ${ }^{131}$ I-MIBG combined with other therapies, the corresponding $\mathrm{p}$ values objective response, $\mathrm{SD}, \mathrm{PD}, \mathrm{MR}$ and occurrence rates of thrombocytopenia and neutropenia were, 0.210, 0.7808, $0.9663,0.1823,0.8347,0.4111$, respectively.

\section{Sensitivity Analysis}

We performed the sensitivity analysis to assess the impacts of each single study on the pooled outcomes. For the analysis of MR in studies of ${ }^{131}$ I-MIBG monotherapy, the sensitivity analysis revealed that result from Garaventa's study may have impacts on the outcomes, suggesting that the study was probably to be the main source of heterogeneity. Nevertheless, after excluding single study one after another, the pooled rates demonstrated the robustness of the results.

\section{Discussion}

Neuroblastoma is the most common extracranial solid tumor in children, and is regarded as the most common malignant tumor in infants so far [47]. Treatment outcomes vary significantly among patients with neuroblastoma, as patients with low risk of neuroblastoma fare well with little or no treatment, whereas high-risk children was diagnosed with metastatic disease or have an eventfree survival (EFS) of approximately 50\% despite multimodality therapeutic schedule that give rise to significant long-term side-effects [48-50]. Iodine-131-metaiodobenzylguanidine ( ${ }^{131} \mathrm{I}$-MIBG) has been used to treat neuroblastoma with a rapid development in recent decades. The efficacy and safety of ${ }^{131}$ I-MIBG therapy remains the most concerned issues. However, the outcomes varied greatly in different investigations. A meta-analysis was conducted by pooling cumulative evidence from institutional reports and some early phase trials to make a more comprehensive evaluation of the efficacy and safety of ${ }^{131}$ I-MIBG therapy in patients with neuroblastoma. The pooled objective response rate in patients treated with 


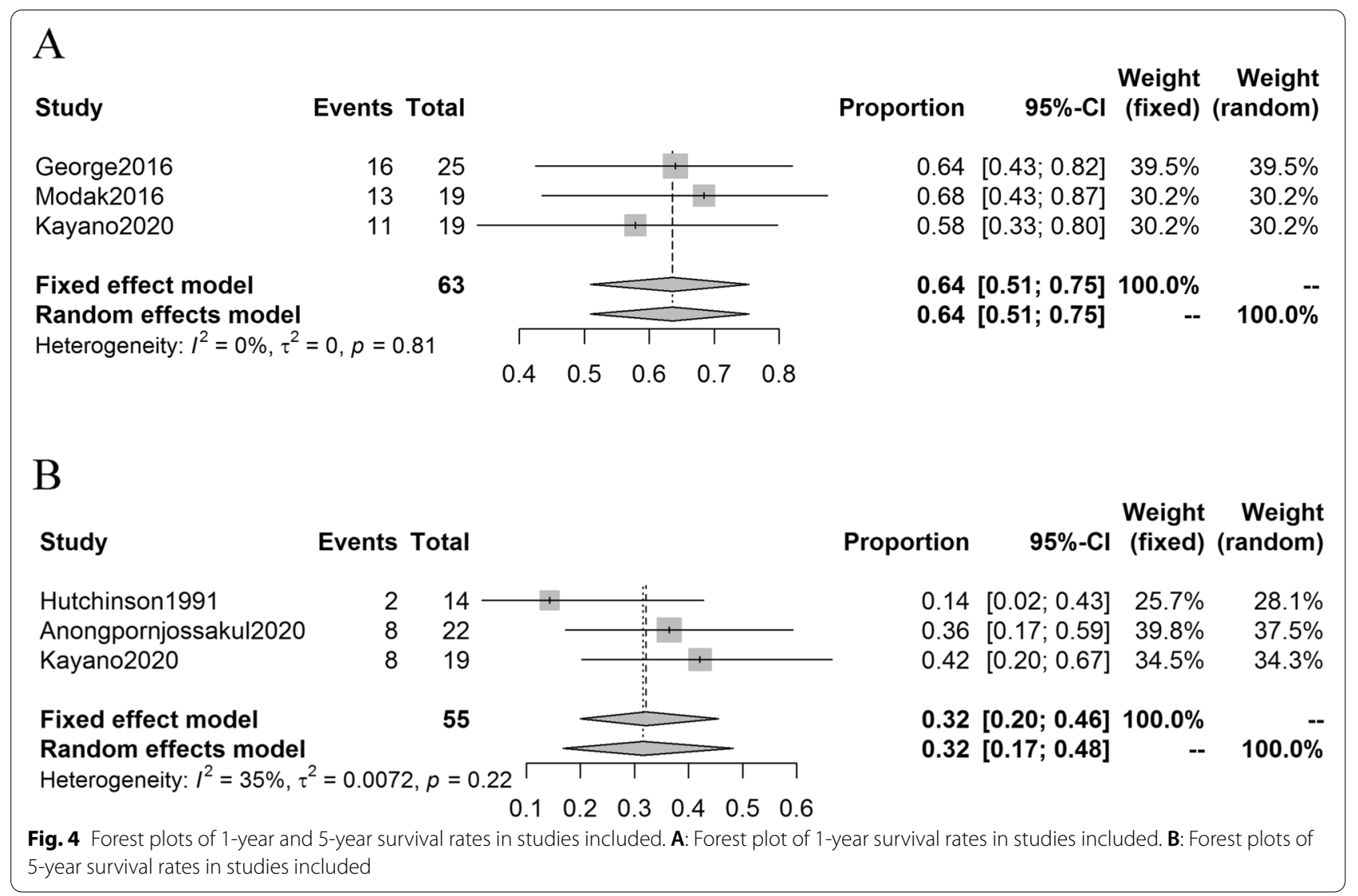

${ }^{131}$ I-MIBG monotherapy and ${ }^{131}$ I-MIBG in combination with other therapies were $39 \%$ and $28 \%$. The reason for this unexpected difference may be that patients in some studies were heavily prior-treated with other therapies. Furthermore, dose heterogeneity among studies could affect the outcomes of therapies and may partially explain the variation in responses. Unfortunately, the schedules varied on study level and we have no access to doses on patient level, in light of this, subgroup analysis based on doses in each study was not performed. With respect to adverse events, thrombocytopenia and neutropenia were the most frequently reported in the majority of investigations enrolled. As found in this study, the pooled occurrence rates of adverse events of ${ }^{131}$ I-MIBG combined with other therapies were higher than that of ${ }^{131}$ I-MIBG alone. Because most patients who receive ${ }^{131}$ I MIBG with other therapies have been treated with several other intensive therapies before and the adverse events of the combined therapy tended to be more common. Furthermore, the pooled 1-year survival and 5-year survival rates in this study were $64 \%$ and $32 \%$.

In this meta-analysis, we did a detailed literature search in Medline, Embase and the Cochrane Library databases to enhance the probability of retrieving all relevant studies as we can. Data extraction was conducted by two independent investigators using a well-designed form. Moreover, the heterogeneity in the studies included was assessed. The results of the meta-analysis showed that there were significant heterogeneities in the majority of indicators. The potential reasons may be attributed to differences in inclusion criteria of the study participants, study design, drug compliance, median lines of prior therapy in each study, batch of drug and other relevant factors. Furthermore, Egger's tests for publication indicated that no potential publication bias was observed in the studies included. Despite the existences of heterogeneity, the results of this analysis may provide hints and assistances for a profile of clinical trials detecting the efficacy and safety of ${ }^{131}$ I-MIBG therapy with larger sample sizes and longer follow-ups.

Our study has provided a comprehensive evaluation of the efficacy and safety of ${ }^{131}$ I-MIBG in the treatment of neuroblastoma. Currently, the best available evidence on the efficacy is derived from several single-arm phase II clinical trials. The findings of this meta-analysis suggest that ${ }^{131} \mathrm{I}-\mathrm{MIBG}$ is an effective agent with acceptable toxicity in patients with neuroblastoma. Due 


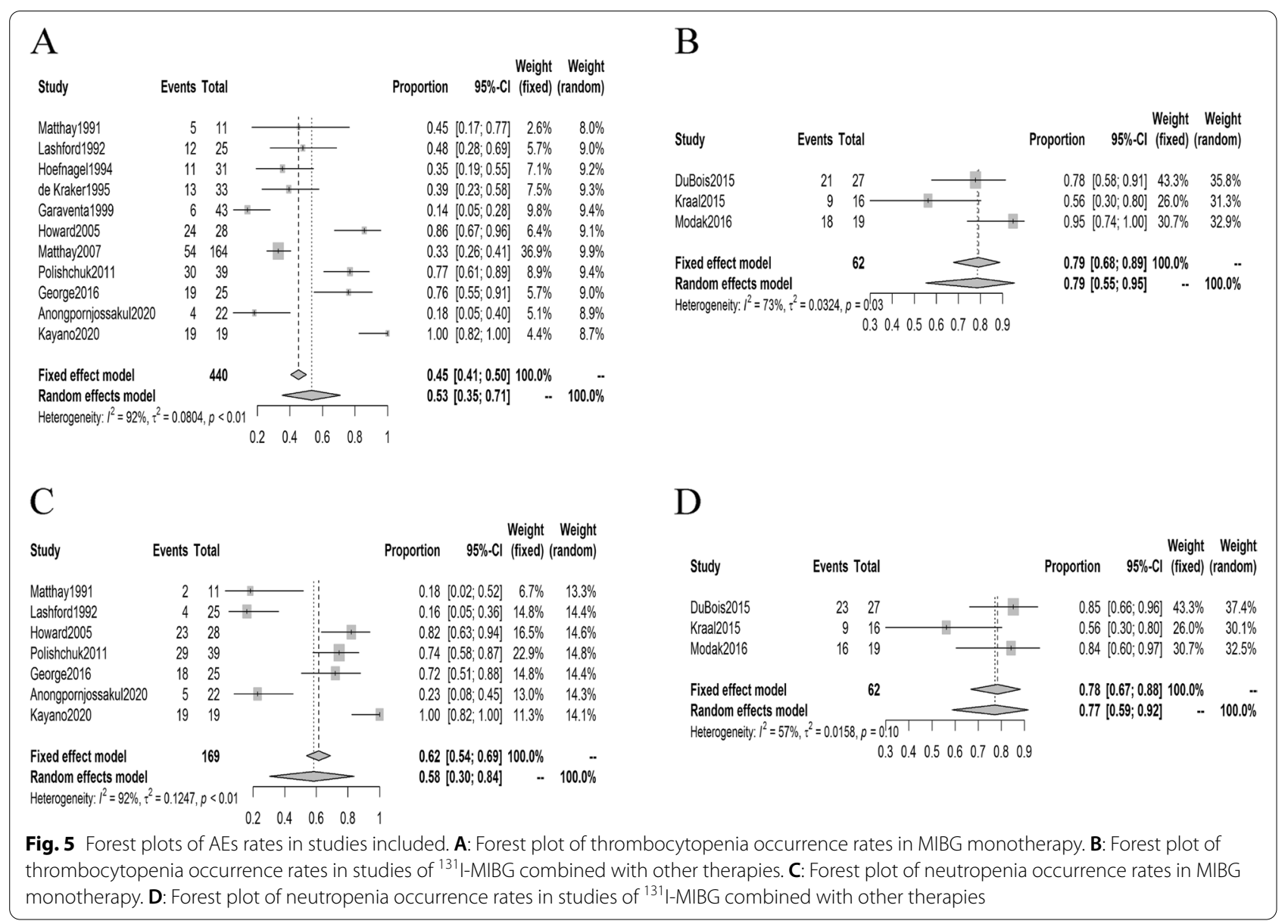

to the heterogeneity of patients' characteristics and low number of relapsed and refractory neuroblastoma, large sample-sized randomized controlled trials are difficult to be performed, nevertheless, individualized ${ }^{131}$ I-MIBG therapy alone or in combination with other agents is recommended in clinical setting.

\section{Acknowledgements}

Thanks to all the authors whose article were included and provided the original research data for this meta-analysis.

\section{Authors' contributions}

$\mathrm{HH}$ conceived and designed this study. $\mathrm{HH}$ and QX were responsible for the collection, extraction, and analysis of the data. $\mathrm{HH}$ and $\mathrm{CY}$ was responsible for writing the paper. CY performed the quality evaluation and completed data analysis. $\mathrm{HH}$ and $\mathrm{CY}$ polished the English language. All authors and participants reviewed the paper and reached an agreement to approve the final manuscript

\section{Funding}

There is no fund support for this study.

\section{Availability of data and materials}

The datasets used and/or analysed during the current study available from the corresponding author on reasonable request.

\section{Declarations}

Ethics approval and consent to participate

Not applicable.

\section{Consent for publication}

Not applicable.

\section{Competing interests}

The authors declare that they have no competing interests.

Received: 18 July 2021 Accepted: 22 February 2022

Published online: 28 February 2022

\section{References}

1. Gurney JG, Davis S, Severson RK, Fang JY, Ross JA, Robison LL. Trends in cancer incidence among children in the U.S. Cancer. 1996;78(3):532-41.

2. Nakagawara A, Li Y, Izumi H, Muramori K, Inada H, Nishi M. Neuroblastoma. Jpn J Clin Oncol. 2018;48(3):214-41.

3. Newman EA, Abdessalam S, Aldrink JH, Austin M, Heaton TE, Bruny J, et al. Update on neuroblastoma. J Pediatr Surg. 2019;54(3):383-9.

4. Matthay KK, Maris JM, Schleiermacher G, Nakagawara A, Mackall CL, Diller L, et al. Neuroblastoma. Nat Rev Dis Primers. 2016;2(1):16078.

5. London WB, Castleberry RP, Matthay KK, Look AT, Seeger RC, Shimada H, Thorner P, Brodeur G, Maris JM, Reynolds CP et al: Evidence for an Age Cutoff Greater Than 365 Days for Neuroblastoma Risk Group Stratification in the Children's Oncology Group. 2005, 23(27):6459-6465. 
6. Cohn SL, Pearson ADJ, London WB, Monclair T, Ambros PF, Brodeur GM, Faldum A, Hero B, lehara T, Machin D et al: The International Neuroblastoma Risk Group (INRG) Classification System: An INRG Task Force Report 2009, 27(2):289-297.

7. Yalcin B, Kremer LC, van Dalen EC: High-dose chemotherapy and autologous haematopoietic stem cell rescue for children with highrisk neuroblastoma. The Cochrane database of systematic reviews 2015(10):Cd006301.

8. Peinemann F, Tushabe DA, van Dalen EC, Berthold F: Rapid COJEC versus standard induction therapies for high-risk neuroblastoma. The Cochrane database of systematic reviews 2015(5):Cd010774.

9. Cougnenc O, Defachelles AS, Carpentier P, Lervat C, Clisant S, Oudoux A, et al. HIGH-DOSE 131I-MIBG THERAPIES IN CHILDREN: FEASIBILITY, PATIENT DOSIMETRY AND RADIATION EXPOSURE TO WORKERS AND FAMILY CAREGIVERS. Radiat Prot Dosim. 2017;173(4):395-404.

10. Peinemann F, van Dalen EC, Tushabe DA, Berthold F: Retinoic acid post consolidation therapy for high-risk neuroblastoma patients treated with autologous hematopoietic stem cell transplantation. The Cochrane database of systematic reviews 2015, 1:Cd010685.

11. Swift CC, Eklund MJ, Kraveka JM, Alazraki AL. Updates in Diagnosis, Management, and Treatment of Neuroblastoma. Radiographics. 2018;38(2):566-80.

12. Hoefnagel CA, Voute PA, de Kraker J, Marcuse HR. Total-body scintigraphy with 1311-meta-iodobenzylguanidine for detection of neuroblastoma. Diagnostic Imaging Clin Med. 1985;54(1):21-7.

13. Bombardieri E, Giammarile F, Aktolun C, Baum RP, Delaloye A, Maffioli L, et al. 131//123I-Metaiodobenzylguanidine (mIBG) scintigraphy: Procedure guidelines for tumour imaging. Eur J Nucl Med Mol Imaging. 2010;37:2436-46

14. Hoefnagel CA, De Kraker J, Valdes Olmos RA, Voute PA. 131I-MIBG as a first-line treatment in high-risk neuroblastoma patients. Nucl Med Commun. 1994;15(9):712-7.

15. De Kraker J, Hoefnagel CA, Caron H, Valdes Olmos RA, Zsiros J, Heij HA, et al. First line targeted radiotherapy, a new concept in the treatment of advanced stage neuroblastoma. Eur J Cancer (Oxford, England : 1990). 1995;31a(4):600-2.

16. Treuner J, Klingebiel T, Feine U, Buck J, Bruchelt G, Dopfer R, et al. Clinical experiences in the treatment of neuroblastoma with 1311-metaiodobenzylguanidine. Pediatr Hematol Oncol. 1986;3:205-16.

17. Garaventa A, Bellagamba O, Lo Piccolo MS, Milanaccio C, Lanino E, Bertolazzi L, et al. 1311-metaiodobenzylguanidine (131I-MIBG) therapy for residual neuroblastoma: a mono-institutional experience with 43 patients. Br J Cancer. 1999;81 (8):1378-84.

18. Howard JP, Maris JM, Kersun LS, Huberty JP, Cheng SC, Hawkins RA, et al. Tumor response and toxicity with multiple infusions of high dose 131I-MIBG for refractory neuroblastoma. Pediatr Blood Cancer. 2005;44(3):232-9.

19. Matthay KK, Yanik G, Messina J, Quach A, Huberty J, Cheng SC, et al. Phase II study on the effect of disease sites, age, and prior therapy on response to iodine-131-metaiodobenzylguanidine therapy in refractory neuroblastoma. J Clin Oncol. 2007;25(9):1054-60.

20. Matthay KK, Quach A, Huberty J, Franc BL, Hawkins RA, Jackson H, et al. lodine-131--metaiodobenzylguanidine double infusion with autologous stem-cell rescue for neuroblastoma: a new approaches to neuroblastoma therapy phase I study. J Clin Oncol. 2009;27(7):1020-5.

21. Johnson K, McGlynn B, Saggio J, Baniewicz D, Zhuang H, Maris JM, et al. Safety and efficacy of tandem 1311-metaiodobenzylguanidine infusions in relapsed/refractory neuroblastoma. Pediatr Blood Cancer. 2011;57(7):1124-9.

22. Polishchuk AL, Dubois SG, Haas-Kogan D, Hawkins R, Matthay KK. Response, survival, and toxicity after iodine-131-metaiodobenzylguanidine therapy for neuroblastoma in preadolescents, adolescents, and adults. Cancer. 2011;117(18):4286-93.

23. de Kraker J, Hoefnagel KA, Verschuur AC, van Eck B, van Santen HM, Caron HN. lodine-131-metaiodobenzylguanidine as initial induction therapy in stage 4 neuroblastoma patients over 1 year of age. Eur J Cancer (Oxford, England : 1990). 2008:44(4):551-6.

24. Lashford LS, Lewis IJ, Fielding SL, Flower MA, Meller S, Kemshead JT, et al. Phase I/II study of iodine 131 metaiodobenzylguanidine in chemoresistant neuroblastoma: a United Kingdom Children's Cancer Study Group investigation. J Clin Oncol. 1992;10(12):1889-96.
25. Moher D, Liberati A, Tetzlaff J, Altman DG. Preferred reporting items for systematic reviews and meta-analyses: the PRISMA statement. Int J Surg (London, England). 2010;8(5):336-41.

26. Stang A. Critical evaluation of the Newcastle-Ottawa scale for the assessment of the quality of nonrandomized studies in meta-analyses. Eur J Epidemiol. 2010;25(9):603-5.

27. Higgins JPT, Thompson SG, Deeks JJ, Altman DG. Measuring inconsistency in meta-analyses. BMJ. 2003;327(7414):557.

28. Hutchinson RJ, Sisson JC, Miser JS, Zasadny KR, Normolle DP, Shulkin BL, et al. Long-term results of [1311] metaiodobenzylguanidine treatment of refractory advanced neuroblastoma. J Nuclear Biology Med (Turin, Italy : 1991). 1991;35(4):237-40.

29. Klingebiel T, Berthold F, Treuner J, Schwabe D, Fischer M, Feine U, et al. Metaiodobenzylguanidine ( $\mathrm{mlBG}$ ) in treatment of 47 patients with neuroblastoma: results of the German Neuroblastoma Trial. Med Pediatr Oncol. 1991;19(2):84-8.

30. Matthay KK, Huberty JP, Hattner RS, Ablin AR, Engelstad BL, Zoger S, et al. Efficacy and safety of [1311] metaiodobenzylguanidine therapy for patients with refractory neuroblastoma. J Nuclear Biology Med (Turin, Italy : 1991). 1991;35(4):244-7.

31. Troncone L, Rufini V, Riccardi R, Lasorella A, Mastrangelo R: The use of [1311] metaiodobenzylguanidine in the treatment of neuroblastoma after conventional therapy. Journal of nuclear biology and medicine (Turin, Italy: 1991) 1991, 35(4):232-236.

32. Brodeur GM, Pritchard J, Berthold F, Carlsen NL, Castel V, Castelberry RP, et al. Revisions of the international criteria for neuroblastoma diagnosis, staging, and response to treatment. J Clin Oncol. 1993;1 1 (8):1466-77.

33. Therasse P, Arbuck SG, Eisenhauer EA, Wanders J, Kaplan RS, Rubinstein $L$, et al. New guidelines to evaluate the response to treatment in solid tumors. European Organization for Research and Treatment of Cancer, National Cancer Institute of the United States, National Cancer Institute of Canada. J Natl Cancer Inst. 2000;92(3):205-16.

34. Mastrangelo S, Rufini V, Ruggiero A, Di Giannatale A, Riccardi R. Treatment of advanced neuroblastoma in children over 1 year of age: the critical role of ${ }^{131}$-metaiodobenzylguanidine combined with chemotherapy in a rapid induction regimen. Pediatr Blood Cancer. 2011;56(7):1032-40.

35. DuBois SG, Chesler L, Groshen S, Hawkins R, Goodarzian F, Shimada $\mathrm{H}$, et al. Phase I study of vincristine, irinotecan, and ${ }^{131} \mid$-metaiodobenzylguanidine for patients with relapsed or refractory neuroblastoma: a new approaches to neuroblastoma therapy trial. Clin Cancer Res. 2012;18(9):2679-86.

36. Kushner BH, Modak S, Kramer K, Basu EM, Roberts SS, Cheung NK. 5-day/5-drug myeloablative outpatient regimen for resistant neuroblastoma. Bone Marrow Transplant. 2013;48(5):642-5.

37. DuBois SG, Allen S, Bent M, Hilton JF, Hollinger F, Hawkins R, et al. Phase I/II study of (131)I-MIBG with vincristine and 5 days of irinotecan for advanced neuroblastoma. Br J Cancer. 2015;112(4):644-9.

38. DuBois SG, Groshen S, Park JR, Haas-Kogan DA, Yang X, Geier E, et al. Phase I Study of Vorinostat as a Radiation Sensitizer with 1311-Metaiodobenzylguanidine (1311-MIBG) for Patients with Relapsed or Refractory Neuroblastoma. Clin Cancer Res. 2015;21(12):2715-21.

39. Kraal KC, Tytgat GA, van Eck-Smit BL, Kam B, Caron HN, van Noesel M. Upfront treatment of high-risk neuroblastoma with a combination of 131I-MIBG and topotecan. Pediatr Blood Cancer. 2015;62(11):1886-91.

40. Yanik GA, Villablanca JG, Maris JM, Weiss B, Groshen S, Marachelian A, et al. 1311-metaiodobenzylguanidine with intensive chemotherapy and autologous stem cell transplantation for high-risk neuroblastoma. A new approaches to neuroblastoma therapy (NANT) phase Il study. Biol Blood Marrow Transplantation. 2015;21(4):673-81.

41. George SL, Falzone N, Chittenden S, Kirk SJ, Lancaster D, Vaidya SJ, et al. Individualized 1311 -mIBG therapy in the management of refractory and relapsed neuroblastoma. Nucl Med Commun. 2016;37(5):466-72.

42. Modak S, Zanzonico P, Carrasquillo JA, Kushner BH, Kramer K, Cheung NK, et al. Arsenic Trioxide as a Radiation Sensitizer for 1311-Metaiodobenzylguanidine Therapy: Results of a Phase II Study. J Nuclear Med. 2016;57(2):231-7.

43. Genolla J, Rodriguez T, Minguez P, Lopez-Almaraz R, Llorens V, Echebarria A. Dosimetry-based high-activity therapy with (131)l-metaiodobenzylguanidine ((131)I-mIBG) and topotecan for the treatment of high-risk refractory neuroblastoma. Eur J Nucl Med Mol Imag. 2019;46(7):1567-75. 
44. Anongpornjossakul Y, Sriwatcharin W, Thamnirat K, Chamroonrat W, Kositwattanarerk A, Utamakul C, et al. lodine-131 metaiodobenzylguanidine (1311-mIBG) treatment in relapsed/refractory neuroblastoma. Nucl Med Commun. 2020.

45. Eisenhauer EA, Therasse P, Bogaerts J, Schwartz LH, Sargent D, Ford $R$, et al. New response evaluation criteria in solid tumours: revised RECIST guideline (version 1.1). Eur J Cancer (Oxford, England : 1990). 2009;45(2):228-47.

46. Kayano D, Wakabayashi H, Nakajima K, Kuroda R, Watanabe S, Inaki A, et al. High-dose (131)I-metaiodobenzylguanidine therapy in patients with high-risk neuroblastoma in Japan. Ann Nucl Med. 2020.

47. Macfarland S, Bagatell R. Advances in neuroblastoma therapy. Curr Opin Pediatr. 2019;31(1):14-20.

48. Kreissman S, Seeger R, Matthay K, London W, Sposto R, Grupp S, et al. Purged Versus Non-Purged Peripheral Blood Stem-Cell Transplantation for High-Risk Neuroblastoma (COG A3973): A Randomised Phase 3 Trial. Lancet Oncol. 2013;14.

49. Ladenstein R, Pötschger U, Pearson ADJ, Brock P, Luksch R, Castel V, et al. Busulfan and melphalan versus carboplatin, etoposide, and melphalan as high-dose chemotherapy for high-risk neuroblastoma (HR-NBL1/SIOPEN): an international, randomised, multi-arm, open-label, phase 3 trial. Lancet Oncol. 2017;18(4):500-14.

50. Elzembely MM, Dahlberg AE, Pinto N, Leger KJ, Chow EJ, Park JR, et al. Late effects in high-risk neuroblastoma survivors treated with high-dose chemotherapy and stem cell rescue. 2019;66(1):e27421.

\section{Publisher's Note}

Springer Nature remains neutral with regard to jurisdictional claims in published maps and institutional affiliations.

- fast, convenient online submission

- thorough peer review by experienced researchers in your field

- rapid publication on acceptance

- support for research data, including large and complex data types

- gold Open Access which fosters wider collaboration and increased citations

- maximum visibility for your research: over $100 \mathrm{M}$ website views per year

At BMC, research is always in progress.

Learn more biomedcentral.com/submissions 